\title{
Sickness absence caused by chest diseases in relation to smoking and chronic bronchitis symptoms
}

\author{
W. JEDRYCHOWSKI \\ Department of Epidemiology, Institute of Social Medicine, Medical School in Kraków, Poland
}

\begin{abstract}
Jẹdrychowski, W. (1976). British Journal of Industrial Medicine, 33, 243-248. Sickness absence caused by chest diseases in relation to smoking and chronic bronchitis symptoms. The relationship between sickness absence caused by chest diseases, smoking habit, and symptoms of chronic bronchitis among the workers of a fertilizer factory in Kraków is examined. The analysis of absence was based on the spells and days of absence registered during a period of six years. The results show that the group of workers with symptoms of chronic bronchitis had many more spells and days of absence caused by chest diseases than persons free from these symptoms. The activity and chronicity of bronchitis symptoms strongly influenced the level of absence, but the role of smoking was not so evident. From the results obtained it appears that analysis of absence can be a valid screening test in the detection of chronic chest diseases, the frequency of which can easily be estimated from absence data.
\end{abstract}

\begin{abstract}
Absence caused by illnesses and accidents is not only a health and social problem but an economic one universally. Among the main reasons for sickness absence, chest diseases are the most serious and most frequent. Although much attention is given to the problem this complex phenomenon should be studied thoroughly so that practical guidelines can be given to physicians in charge of the health of workers.

The aim of the paper was to verify the hypothesis that illness caused by chest diseases is particularly frequent in workers with chronic chest diseases that are non-specific. As there is evidence that the smoking habit is the strongest factor in the aetiology of these diseases it would be useful to know whether the risk of sickness absence caused by chest diseases is much higher in smokers than in non-smoking workers.
\end{abstract}

\section{Material and methods}

Sickness absence was analysed for an epidemiological prospective study on chronic non-specific chest diseases in the population of the inhabitants of Kraków(Brzeziński et al., 1972). The study which began in 1968 also included workers of the fertilizer factory situated in the city. Out of 248 male workers examined in 1968 only 197 persons were re-examined in 1973 , that is, $79.4 \%$ of the population covered in the first field study.

In the first cross-sectional study performed in 1968 we used the technique of standardized interviews on those with chronic chest symptoms. These interviews were held in the factory with specially trained interviewers. The questionnaire used was the Polish version of the Medical Research Council's questionnaire on chest symptoms (Brzeziński et al., 1972; Ciba Foundation Symposium, 1959; Medical Research Council, 1965). A diagnosis of chronic bronchitis was made if chronic cough and chronic phlegm were present for a minimum of three consecutive months a year and for at least two successive years. Interviews on chronic chest symptoms of the same person taken twice during a five-year period gave the possibility of measuring the activity and chronicity of chronic bronchitis symptoms.

Thoroughout the period of six years (1967-72) data on sickness absence for the 197 workers included in the project were also collected. Records were kept for each worker at the factory listing spells, days, and causes of illnesses. The analysis gave details of sickness absence caused by chest diseases excluding tuberculosis. ICD 
rubrics included were: $464-466,471-472,480-486,490$ 493, 506, 508, 511, 517-519 (World Health Organization, 1967). Analysis of sickness absence due to other diseases was undertaken separately. Single days of absence were included but the analysis covered only the working days.

In the study special attention was drawn to the group of workers susceptible to sickness caused by chest diseases. A worker who had had more spells of absence or lost more days than the value of the upper quartile was defined as a person susceptible to sickness absence. The median values and the lower and upper quartiles were estimated from the distributions of spells and days separately. According to these premises two separate definitions of susceptibility were employed. A person who

\section{TABLE 1}

Chronic Bronchitis Symptoms in Relation to Smoking Habits of the Workers Examined Prospectively

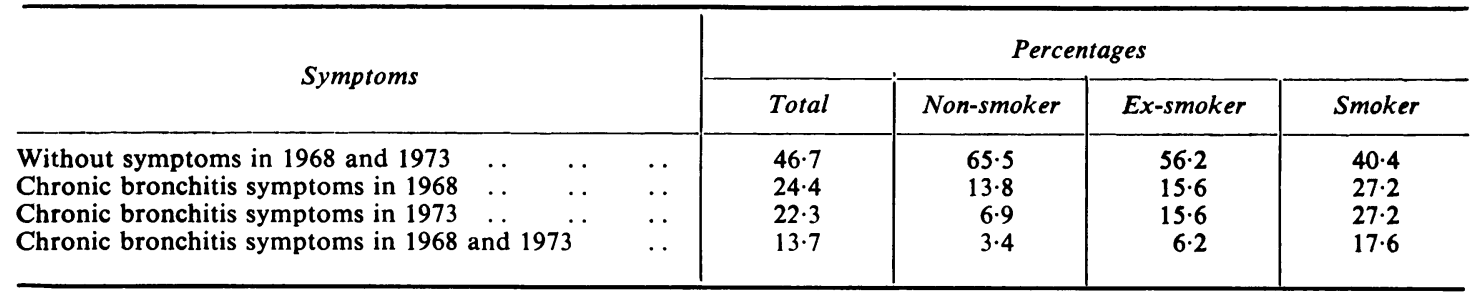

TABLE 2

Sickness Absence Spells Due to Chest Disease (1967-72) in Relation to Chronic Bronchitis SYMPTOMS

\begin{tabular}{|c|c|c|c|c|c|c|c|}
\hline \multirow{2}{*}{\multicolumn{3}{|c|}{ No. of spells }} & \multicolumn{2}{|c|}{ Without chronic bronchitis } & \multicolumn{2}{|c|}{ With chronic bronchitis } & \multirow{2}{*}{ Total } \\
\hline & & & No. & $\%$ & No. & $\%$ & \\
\hline $\begin{array}{l}0 \\
1-2 \\
3-4 \\
5+\end{array}$ & $\begin{array}{l}\ldots \\
\cdots \\
\cdots \\
\cdots\end{array}$ & $\begin{array}{l}\ldots \\
\ldots \\
\ldots \\
\cdots\end{array}$ & $\begin{array}{l}27 \\
75 \\
27 \\
24\end{array}$ & $\begin{array}{l}17.6 \\
49.0 \\
17.6 \\
15.7\end{array}$ & $\begin{array}{r}2 \\
18 \\
6 \\
18\end{array}$ & $\begin{array}{r}4.5 \\
40.9 \\
13.6 \\
40.9\end{array}$ & $\begin{array}{l}29 \\
93 \\
33 \\
42\end{array}$ \\
\hline Total & $\ldots$ & $\cdots$ & 153 & 99.9 & 44 & 99.9 & 197 \\
\hline
\end{tabular}

$\chi^{2}=14.985 . \quad$ DF $=3 . \quad P<0.05$.

TABLE 3

Sickness Absence Days Due to Chest Disease (1967-72) in Relation to Chronic Bronchitis SYMPTOMS

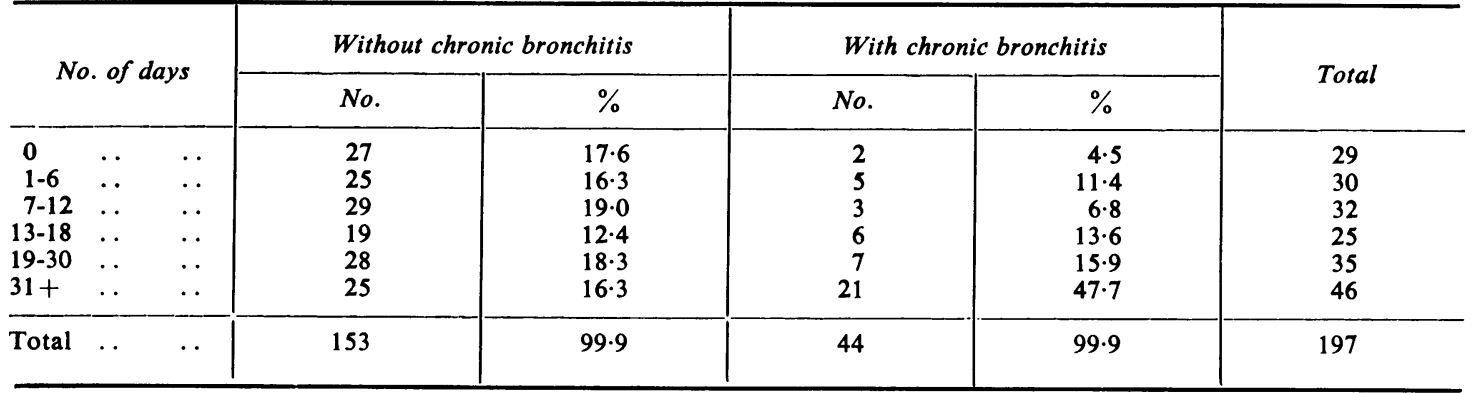

$\chi^{2}=22 \cdot 207 . \quad$ DF $=5 . \quad P<0.05$.

Mean no. of spells

Mean no. of days

Mean no. of days per spell
Without chronic bronchitis

$$
\begin{array}{r}
2 \cdot 38 \\
17 \cdot 39 \\
7 \cdot 29
\end{array}
$$


had had more than five spells of sickness absence or more than 31 days caused by chest diseases during the period of six years was defined as susceptible to absence.

\section{Results}

The difference in age for the groups of workers with several spells or days of absence was not significant statistically (mean age of workers without any spells of absence $45 \cdot 3$ years, and mean age of workers with seven or more spells $48 \cdot 1$ years). Symptoms of chronic bronchitis varied according to the smoking habits of those examined (Table 1). Among persons with symptoms of chronic bronchitis more spells and more days of absence caused by chest diseases were observed than in the group of workers without these symptoms (Tables 2 and 3 ). The data on different smoking categories of workers show that there is a slight difference in the distribution of spells and days of sickness absence due to chest diseases (Tables 4 and 5). However, the joint effect of smoking and symptoms of chronic bronchitis on sickness spells and days (Figs 1 and 2) was more pronounced in cases in which symptoms of chronic bronchitis and smoking were present. It should be emphasized that among the workers who had symptoms of chronic bronchitis we found that twice as many were susceptible to sickness absence than in the other group.

It appeared that the effect of the dynamics and chronicity of chronic bronchitis symptoms was seen especially in the older group of persons examined (Table 6). In other words one can conclude that in older bronchitics absence is influenced to a greater extent by the activity and chronicity of chronic bronchitis symptoms than in younger ones.

It is worthwhile mentioning that there was no difference in the distribution of spells and days of sickness absence caused by other diseases with regard to the smoking categories or chronic bronchitis symptoms.

Using the conditional probability formula (Baye's theorem: appendix) one can estimate the probability that a given individual is sick, provided the proportion of actual cases in the population being examined,

TABLE 4

Sickness Absence Spells Due to Chest Disease (1967-72) in Relation to Smoking Habit

\begin{tabular}{|c|c|c|c|c|c|c|c|c|}
\hline \multirow{2}{*}{\multicolumn{2}{|c|}{ No. of spells }} & \multicolumn{2}{|c|}{ Non-smokers } & \multicolumn{2}{|c|}{ Ex-smokers } & \multicolumn{2}{|c|}{ Smokers } & \multirow{2}{*}{ Total } \\
\hline & & No. & $\%$ & No. & $\%$ & No. & $\%$ & \\
\hline $\begin{array}{l}0 \\
1-2 \\
3-4 \\
5+\end{array}$ & $\begin{array}{l}\ldots \\
\cdots \\
\cdots \\
.\end{array}$ & $\begin{array}{r}7 \\
13 \\
4 \\
5\end{array}$ & $\begin{array}{l}24 \cdot 1 \\
44 \cdot 8 \\
13 \cdot 8 \\
17 \cdot 2\end{array}$ & $\begin{array}{r}7 \\
13 \\
7 \\
5\end{array}$ & $\begin{array}{l}21 \cdot 9 \\
40 \cdot 6 \\
21 \cdot 9 \\
15 \cdot 7\end{array}$ & $\begin{array}{l}15 \\
67 \\
22 \\
32\end{array}$ & $\begin{array}{l}11 \cdot 0 \\
49 \cdot 3 \\
16 \cdot 2 \\
23 \cdot 5\end{array}$ & $\begin{array}{l}29 \\
93 \\
33 \\
41\end{array}$ \\
\hline Total & $\ldots$ & 29 & $99 \cdot 7$ & 32 & $100 \cdot 0$ & 136 & $99 \cdot 7$ & 197 \\
\hline
\end{tabular}

$\chi^{2}=6.324 . \quad \mathrm{DF}=6 . \quad \mathrm{P}>0.05$

TABLE 5

Sickness Absence Days Due to Chest Disease (1967-72) in Relation to Smoking Habit

\begin{tabular}{|c|c|c|c|c|c|c|c|c|}
\hline & & & kers & & ers & & & Tatol \\
\hline $\begin{array}{l}0 \\
1-6 \\
7-12 \\
13-18 \\
19-30 \\
31+\end{array}$ & $\begin{array}{ll}\ldots & \ldots \\
\ldots & \ldots \\
\ldots & . \\
\ldots & \ldots \\
\ldots & \ldots \\
\ldots & .\end{array}$ & $\begin{array}{l}7 \\
2 \\
7 \\
2 \\
7 \\
4\end{array}$ & $\begin{array}{r}24 \cdot 1 \\
6 \cdot 9 \\
24 \cdot 1 \\
6 \cdot 9 \\
24 \cdot 1 \\
13 \cdot 8\end{array}$ & $\begin{array}{l}7 \\
3 \\
4 \\
3 \\
7 \\
8\end{array}$ & $\begin{array}{r}21 \cdot 9 \\
9 \cdot 4 \\
12 \cdot 5 \\
9 \cdot 4 \\
21 \cdot 9 \\
25 \cdot 0\end{array}$ & $\begin{array}{l}15 \\
25 \\
21 \\
20 \\
22 \\
33\end{array}$ & $\begin{array}{l}11 \cdot 0 \\
18 \cdot 4 \\
15 \cdot 4 \\
14 \cdot 7 \\
16 \cdot 2 \\
24 \cdot 3\end{array}$ & $\begin{array}{l}29 \\
30 \\
32 \\
25 \\
36 \\
45\end{array}$ \\
\hline Total & . & 29 & 99.9 & 32 & $100 \cdot 0$ & 136 & $100 \cdot 0$ & 197 \\
\hline $\begin{array}{l}\chi^{2}=1 \\
\text { Mean r } \\
\text { Mean r } \\
\text { Mean r }\end{array}$ & $\begin{array}{l}2 \cdot 294 . \\
\text { o. of spell } \\
\text { o. of days } \\
\text { 10. of days }\end{array}$ & 11 & 05 & $\begin{array}{r}\text { Non-smo } \\
2 \cdot 24 \\
18 \cdot 10 \\
7 \cdot 23\end{array}$ & & $\begin{array}{c}\text { Ex-smoke } \\
2.59 \\
20.64 \\
7.95\end{array}$ & & $\begin{array}{c}\text { Smokers } \\
2 \cdot 91 \\
22 \cdot 43 \\
7 \cdot 38\end{array}$ \\
\hline
\end{tabular}


Non-smokers without chronic bronchitis
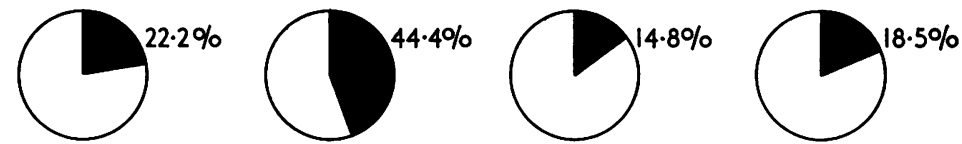

Smokers

without

chronic bronchitis
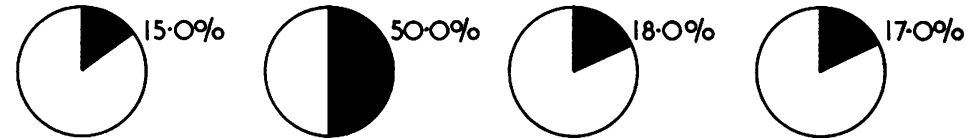

Smokers

with

chronic bronchitis

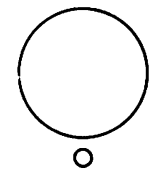

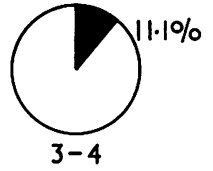

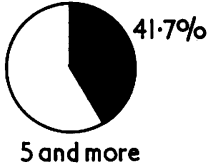

FIG. 1. Distribution of sickness absence spells caused by chest diseases, during a period of six years (1967-72), in relation to smoking and chronic bronchitis symptoms.

Non-smokers
without
chronic bronchitis

Smokers

without

chronic bronchitis

Smokers

with

chronic bronchitis
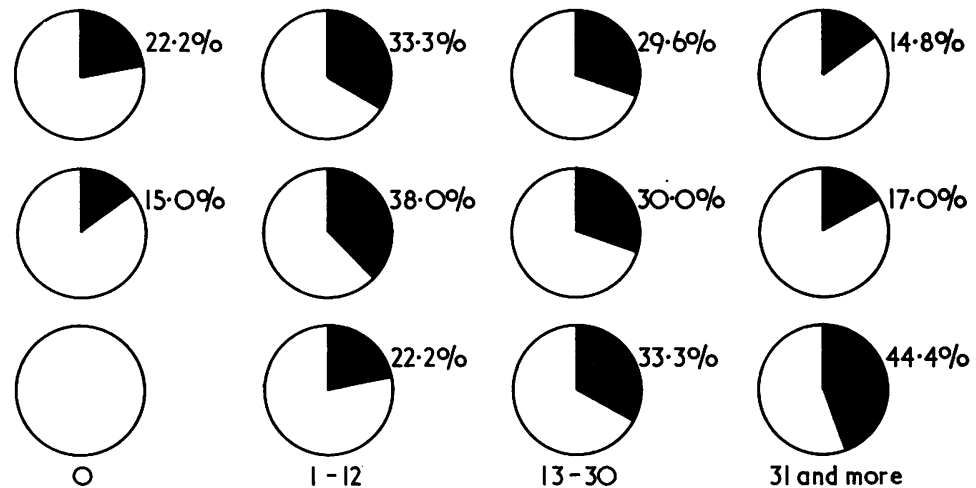

$13-30$

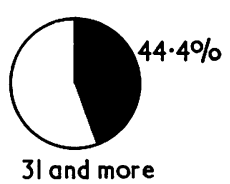

FIG. 2 Distribution of sickness absence days caused by chest diseases, during a period of six years (1967-72), in relation to smoking and chronic bronchitis symptoms.

sensitivity of the screening method, and falsepositive rate are known (Armitage, 1971; Goldberg, 1972).

Using the formula of Baye it was easy to calculate the conditional probability that a person susceptible to sickness absence would have chronic bronchitis symptoms. Of course this probability will depend on the frequency of chronic bronchitis in the population as well as on sensitivity and specificity of the assumed screening criteria based on sickness absence data. As the overall prevalence rate of chronic bronchitis in our material was $22.3 \%$ we could assume from the conditional probability formula that nearly half of the group of workers $(42.2 \%)$ with more than five spells of absence would present chronic bronchitis symptoms. On the other hand it was possible to calculate the probability of chronic bronchitis symptoms for persons with a different pattern of sickness absence due to chest diseases. In this sense Baye's theorem was helpful in evaluating the validity of the screening test on absence data.

\section{Discussion}

The results presented show that the group of persons with symptoms of chronic bronchitis had more spells and days of sickness absence caused by chest diseases than workers who were free from these symptoms. Only a very slight relationship between age and sickness absence was observed, but this could have been because of the narrow age range of the population. However, it was noticed that the degree of activity and chronicity of chronic bronchitis symptoms had some effect on the level of sickness absence caused by chest diseases, especially in the older age group. As the number of people studied was small it was difficult to measure the effect of smoking, and the role and importance of this factor with regard to sickness absence due to chest diseases as well as to other diseases was not clear. If smoking were to increase in a significant way the risk of sickness absence, the absence rates for chest diseases would be significantly higher in smokers 
TABLE 6

Sickness Absence Spells Due to Chest Disease (1967-72) in Relation to Dynamics and Chronicity of Chronic Bronchitis Symptoms

Younger workers (under 40 years)

\begin{tabular}{|c|c|c|c|c|}
\hline Chronic bronchitis & No. & Observed & Expected* & $\frac{\text { Observed }}{\text { Expected }}$ \\
\hline $\begin{array}{l}\text { Without symptoms of chronic bronchitis in } 1968 \text { and } \\
1973 \quad \ldots \text { of chronic bronchitis in } 1968 \text {, without } \\
\text { Symptoms of } \\
\text { symptoms in } 1973 \quad \ldots \\
\text { Without symptoms of chronic bronchitis in } 1968 \text {, but } \\
\text { symptoms in } 1973 \quad \ldots \\
\text { Symptoms of chronic bronchitis in } 1968 \text { and } 1973 \quad \ldots\end{array}$ & $\begin{array}{r}48 \\
5 \\
2 \\
3\end{array}$ & $\begin{array}{r}121 \\
10 \\
9 \\
11\end{array}$ & $\begin{array}{r}124 \cdot 80 \\
13 \cdot 00 \\
5 \cdot 20 \\
7 \cdot 80\end{array}$ & $\begin{array}{l}0.96 \\
0.76 \\
1.73 \\
1.41\end{array}$ \\
\hline $\begin{array}{llllllll}\text { Total } & \ldots & \ldots & \ldots & \ldots & \ldots & \ldots & \ldots\end{array}$ & 58 & 151 & $150 \cdot 80$ & $1 \cdot 00$ \\
\hline \multicolumn{5}{|l|}{$\begin{array}{l}\overline{\mathrm{x}}=2.60 . \quad x^{2}=4.898 . \quad \mathrm{DF}=3 . \quad \mathrm{P}>0.05 \\
\text { Older workers (more than } 40 \text { years) }\end{array}$} \\
\hline Chronic bronchitis & No. & Observed & Expected ${ }^{*}$ & $\frac{\text { Observed }}{\text { Expected }}$ \\
\hline 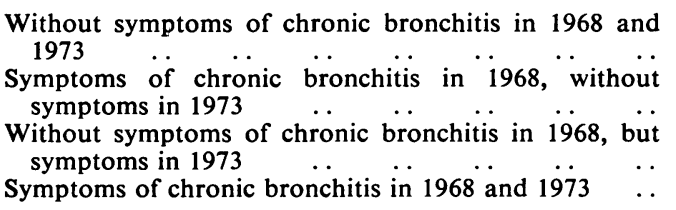 & $\begin{array}{l}84 \\
16 \\
\\
15 \\
24\end{array}$ & $\begin{array}{r}164 \\
67 \\
\\
63 \\
96\end{array}$ & $\begin{array}{r}235 \cdot 20 \\
44 \cdot 80 \\
42 \cdot 00 \\
67 \cdot 20\end{array}$ & $\begin{array}{l}0.70 \\
1.50 \\
1 \cdot 50 \\
1 \cdot 43\end{array}$ \\
\hline Total & 139 & 390 & $389 \cdot 20$ & 1.00 \\
\hline
\end{tabular}

$\overline{\mathrm{x}}=2 \cdot 80 . \quad \chi^{2}=55 \cdot 398 . \quad \mathrm{DF}=3 . \quad \mathrm{P}<0.05$.

*Expected rates were derived for each category of age separately multiplying number of cases in the rows and mean number of spells per man

than in non-smokers. One can conclude from the results obtained that smoking, being one of the strongest factors in the aetiology of chronic nonspecific chest disease in the course of which acute exacerbations often take place, is responsible indirectly for the increased level of sickness absence.

The analysis of absence in relation to chronic bronchitis symptoms and smoking habit was extended by the observation of persons susceptible to absence. The idea of 'personal liability to sickness absence' was introduced several years ago by Taylor (1968a and b). Nearly half the group of workers defined as susceptible had symptoms of chronic bronchitis. Special care ought to be given to this group of workers by physicians in factories. Such a group of workers should undergo detailed medical examinations for chronic chest disease or special environmental analysis ought to be performed in each case. The analysis of sickness absence may serve as a valuable source of information on overall frequency of chronic chest symptoms in a given industrial population and the findings should stimulate industrial physicians to give more attention to analysis of sickness absence data.

This research was carried out under the patronage of the Scientific Programme Council for Studies on Chronic Respiratory Diseases in Kraców. Chairman: Prof.dr Jan Kostrzewski.

This work was partly supported by a grant under contract NCHS PI 1 with the National Center for Health Statistics, Washington, D.C., Director of the Study: Prof.dr F. Sawicki.

\section{References}

Armitage, P. (1971). Statistical Methods in Medical Research. Blackwell, Oxford.

Brzeziński, Zb., Sawicki, F., et al. (1972). Ecology of chronic and non-specific respiratory diseases. In Proceedings of an International Symposium. PZWL (State Medical Publishing House), Warsaw.

Ciba Foundation Symposium (1959). Terminology, 
definitions, and classifications of chronic pulmonary emphysema and related conditions. Thorax, 14, 286299.

Goldberg, D. P. (1972). The Detection of Psychiatric Illness by Questionnaire. Oxford University Press, London.

Medical Research Council (1965). Definition and classification of chronic bronchitis for clinical and epidemiological purposes: A report by the Committee on Aetiology of Chronic Bronchitis. Lancet, 1, 775-779.

Taylor, P. J. (1968a). A study of 194 men with contrasting sickness absence experience in a refinery population. British Journal of Industrial Medicine, 25, 106-118.

- (1968b). Sickness absence resistance. Transactions of the Society of Occupational Medicine, 18, 96-100.

World Health Organization (1967). International Classification of Diseases, 8th edition. WHO, Geneva.

\section{Appendix}

The conditional probability was calculated according to the following formula:

$$
P_{d_{(i)}}=\frac{P \cdot p_{i}}{P \cdot p_{1}+Q \cdot p_{2}}
$$

$\mathbf{P}_{\mathrm{d}_{(\mathbf{i})}}=$ probability that a given individual is diseased,

$\mathbf{P}^{(1)}=$ proportion of actual cases in the population (prevalence),

$\mathrm{p}_{1}=$ proportion of actual cases of disease diagnosed correctly by screening test (sensitivity),

$\mathbf{P}_{\mathbf{2}} \quad$ = proportion of normals identified by the test as cases (false positive rate).

Received for publication 18 December 1975

Accepted for publication 5 May 1976 